Journal of Food Science

Volume 72 Issue 6 Page C313-C316, August 2007

http://dx.doi.org/10.1111/j.1750-3841.2007.00410.x

(c) 2007 Blackwell Publishing, Inc.
Archimer, archive institutionnelle de l'Ifremer http://www.ifremer.fr/docelec/

The definitive version is available at www.blackwell-synergy.com

\title{
Effect of High Pressure on the Calpain-Calpastatin System in Fish Muscle
}

\author{
Romuald Chéret ${ }^{1,2}$, Christine Delbarre-Ladrat ${ }^{2}$, \\ Véronique Verrez-Bagnis ${ }^{2}$, Marie de Lamballerie ${ }^{1^{*}}$
}

1 UMR CNRS 6144 GEnie des Procédés Environnement et Agroalimentaire, École Nationale d'Ingénieurs des Techniques des Industries Agricoles et Alimentaires, BP 82225, 44322, Nantes Cedex 3, France

2 IFREMER, Rue de l'lle d'Yeu, BP 21105, 44311 Nantes Cedex 3, France

*corresponding author: anton@enitiaa-nantes.fr:

\begin{abstract}
:
Calpains (calcium-activated neutral proteases) of sea bass (Dicentrarchus labrax L.) muscle may participate in the degradation of muscle tissue during postmortem storage. These enzymes are regulated by calpastatin, their endogenous specific inhibitor. The objective of this study was to evaluate the changes encountered by the calpain system during the postmortem storage of fish muscle after high-pressure treatment. From $100 \mathrm{MPa}$, high-pressure treatment of purified calpains results in a loss of their activity as well as in the dissociation of the heterodimeric form. In muscle, the high-pressure processing decreases the initial activity of calpain. This loss in activity may be due to an inactivation by a change of structure. Initial calpastatin activity is not modified by the high-pressure treatment, but it decreases during the storage from the beginning for a treatment at $300 \mathrm{MPa}$ after which calpastatin is stable during $2 \mathrm{~d}$. Therefore, this study also suggests that high-pressure treatment could be a useful way to improve fish flesh quality.
\end{abstract}

Keywords: high pressure; postmortem denaturation; calpain system 


\section{Introduction}

During postmortem storage, fish muscle undergoes degradation and the flesh quality

30 decreases rapidly depending on the fish species. Loss of freshness, one of the most important

31 aspects of raw fish, is often caused by a combination of physical, biochemical (enzymatic

32 degradation), and microbiological reactions. Calpains are the enzymes often described to be

33 involved in postmortem tenderization (Jiang 2000). The calpains (EC 3.4.22.17) are intracellular

34 endopeptidases requiring calcium for their enzymatic activity. These proteases are ubiquitously

35 distributed in cells of various organisms (insects, plants,etc), but some isoforms are tissue-

36 specific. Two isoforms are widely present in muscle: $\mu$-calpain (requiring 5-50 $\mu \mathrm{M} \mathrm{Ca}^{2+}$ to be

37 activated) and m-calpain (150-1000 $\mu \mathrm{M} \mathrm{Ca}^{2+}$ ). In sea bass muscle (Dicentrarchus labrax L.), 3

38 different isoforms have been identified and are differently expressed according to the season

39 (Ladrat and others 2000). The calpains are heterodimers composed of a large subunit and a small

40 subunit with a molecular weight of about $80 \mathrm{kDa}$ and $28 \mathrm{kDa}$, respectively. The large subunit has

41 a catalytic role and the small subunit a regulatory role. In the presence of calcium ions, the

42 heterodimer is dissociated and also autolyzed (self-digested). Calpain is active as the dissociated

43 form (Saido and others 1994; Goll and others 2003), although this is a controversial subject

44 (Saido and others 1994; Bessière and others 1999b; Goll and others 2003). Moreover, these

45 enzymes are regulated by an endogenous specific inhibitor, calpastatin.

46 High-pressure treatment is an innovative food preservation technology. High-pressure is

47 an alternative to thermal or chemical treatment. This new technology causes inactivation of

48 pathogenic and spoilage micro-organisms in foods (Yuste and others 2001). It also exhibits

49 other numerous advantages; among them are no vitamin $\mathrm{C}$ loss, fresher taste, and better

50 appearance, as well as better textural and nutritional qualities compared to other classical

51 processing. High-pressure processing responds to the consumer demands for safer products. On 
52 top of that, consumers do not have negative feeling about this process compared to irradiation

53 treatment (Deliza and others 2005). Generally, the products are treated in the range of 100 to

$541000 \mathrm{MPa}$, for 5 to $20 \mathrm{~min}$. High-pressure processing affects chemical bonds of molecules, and

55 therefore may also induce modifications in water, proteins, polysaccharides and lipids. This

56 treatment can modify the hydrostatic and electrostatic molecular interactions with important

57 consequences for the secondary, tertiary, and quaternary structures of proteins. In fish muscle,

58 this processing affects enzymatic activities (Angsupanich and Ledward 1998; Ashie and

59 Simpson 1996), as well as structural proteins (Ohshima and others 1993).

60 The objectives of this study were to identify the effects of the pressure treatment on the

61 calpain system of sea bass (Dicentrarchus labrax L.) muscle upon refrigerated postmortem

62 storage, as well as to gain an insight into the behavior of the calpain system in fish flesh treated

63 by high pressure.

\section{Materials and Methods}

66 Materials

Unless specified, chemicals were purchased from Sigma-Aldrich (Saint-Quentin Fallavier,

68 France). The chromatographic gels were from Amersham Biosciences (Uppsala, Sweden).

\section{$70 \quad$ Preparation of the fish samples}

Alive sea bass (Dicentrarchus labrax L.), 4 years old, with an average weight of $325 \mathrm{~g}$

72 and total length of $30 \mathrm{~cm}$ were collected from a local aquaculture farm ("Les Viviers du Gois",

73 Beauvoir-sur-Mer, France) and brought back alive to the laboratory. Fish were killed by

74 decapitation. Dorsal white muscle was excised and skinned in prerigor conditions. 
Preparation of sarcoplasmic proteins from sea bass muscle

Frozen minced muscle (25 g) was homogenized twice for $30 \mathrm{~s}$ with an Ultra Turrax T25

(IKA Labortechnik, Staufen, Germany) equipped with an 18-mm-diameter head (S 25- 18 G) in

$75 \mathrm{~mL}$ of buffer A containing $50 \mathrm{mM}$ Tris- $\mathrm{HCl}(\mathrm{pH} 7.5), 10 \mathrm{mM} \beta$-mercaptoethanol, and $1 \mathrm{mM}$

80 ethylenediaminetetraacetic acid (EDTA). After centrifugation at $10000 \mathrm{x} \mathrm{g}$ (Model GR 20.22;

81 Jouan, France) at $10000 x \mathrm{x}$ for $40 \mathrm{~min}$ at $10{ }^{\circ} \mathrm{C}$, the supernatant was filtered through a $0.45-\mu \mathrm{m}$

82 filter (Sartorius AG, Goettingen, Germany). Three sarcoplasmic extracts were realized for each

83 pressure treatment and for each postmortem storage day.

\section{Purification of calpains from muscle}

86 The entire procedure following a method previously decribed (Ladrat and others, 2000) was

87 carried out at $4{ }^{\circ} \mathrm{C}$ and with an Akta basic (Amersham Biosciences, Uppsala, Sweden)

88 chromatographic equipment. The first chromatographic column (Phenyl Sepharose, Ø $26 \mathrm{~mm}, \mathrm{~L}$

$8910.5 \mathrm{~cm}$ ) was balanced with equilibration buffer composed of $50 \%$ buffer A and $50 \%$ buffer B

90 (buffer A with $1 \mathrm{M} \mathrm{NaCl}$ ).

91 Sarcoplasmic extract $(50-\mathrm{mL})$ with $0.5 \mathrm{M} \mathrm{NaCl}$ (final concentration) was directly applied

92 to the chromatographic column. The nonabsorbed proteins, including calpastatin, the endogenous

93 inhibitor of calpains, were washed with the equilibration buffer. The calpain active fraction was

94 then eluted in batch with $60 \mathrm{ml}$ buffer $\mathrm{A}$.

95 The calpain active fraction eluted during the purification by hydrophobic interaction

96 chromatography was run to the DEAE Sepharose (16 mm diameter, $16 \mathrm{~cm} \mathrm{long,} 1.5 \mathrm{~mL} / \mathrm{min}$ ) in

97 buffer A. The elution was carried out with a 500-mL 0-400 mM NaCl gradient in buffer A. Only

98 one peak containing active calpain was observed. The calpain active fractions recoved at $300 \mathrm{mM}$

$99 \mathrm{NaCl}$ elution were collected $(5 \mathrm{ml})$. 


\section{$101 \quad$ High-Pressure Processing}

102 Two sample types were submitted to high-pressure treatment: muscle fillets at fish death before

103 postmortem storage at $4{ }^{\circ} \mathrm{C}$ and calpain extract. To reduce the effect of individual fish variation, 104 both dorsal fillets of each fish (a number of 12 fish in total) were divided into portions and mixed

105 to finally obtain 12 homogenous samples, each about $100 \mathrm{~g}$. Prior to pressure processing, muscle

106 portions and calpain extracts were individually packed under vacuum in polyethylene bags (La

107 Bovida, Le Subdray, France). High-pressure processing was carried out in a 3.5-L reactor unit

108 (ACB Pressure Systems, Nantes, France) equipped with temperature and pressure regulatory

109 devices. The samples were subsequently subjected to high-pressure treatment: the levels of

110 pressurization ranged from 0.1 to $500 \mathrm{MPa}( \pm 7 \mathrm{MPa})$ for $5 \mathrm{~min}$. The expected high-pressure was

111 reached at $3 \mathrm{MPa}^{-1}{ }^{-1}$, and after $5 \mathrm{~min}$ of treatment it was then released at $250 \mathrm{MPa} \cdot \mathrm{s}^{-1}$.

112 Temperature of transmitting medium in the vessel was settled at $10^{\circ} \mathrm{C}\left( \pm 5^{\circ} \mathrm{C}\right)$. Temperature of

113 the cooling jacket which surrounded the pressure vessel was also maintained at $10{ }^{\circ} \mathrm{C}$ during the

114 pressure treatment. One thermocouple, K-type (0.3 mm diameter; Omega, Stamford, Connecticut,

115 USA), positioned close to the sample allowed to follow temperature variation during treatment.

\section{Storage of fillet}

118 In our experiment, samples (portion of $100 \mathrm{~g}$ ) treated at $0.1,100$ and $300 \mathrm{MPa}$ were stored 119 at $4{ }^{\circ} \mathrm{C}$ from 0 to 7 days. At the end of the appropriate storage period, triplicates of $30 \mathrm{~g}$ each 120 were minced, vacuum-packed and frozen at $-80{ }^{\circ} \mathrm{C}$ until use for enzymatic analysis.

\section{Determination of protein amounts}


124 others (1949) with bovine serum albumin solution as the standard. The values were the means of

1253 measurements for each sample.

126

127 Calpain activity measurement

128 Calpain activity was determined at $30{ }^{\circ} \mathrm{C}$ in a $303-\mu \mathrm{L}$ reaction mixture containing $3 \mu \mathrm{L}$ of

$1290.5 \mathrm{M} \mathrm{CaCl}, 6 \mu \mathrm{L}$ of $5 \%$ CHAPS \{3-[3-(cholamidopropyl)-dimethyl-ammonio]-1-

130 propanesulfonate $\}$ and $5 \mu \mathrm{l}$ of $20 \mathrm{mM}$ synthetic fluorogenic substrate SucLT (N-succinyl-Leu-

131 Tyr-7-amido-4-methylcoumarin) prepared in methanol. The reaction was initiated by adding 255

$132 \mu \mathrm{L}$ of calpain active fraction. During a 40-min reaction, fluorescence was monitored in

133 microplate wells using the spectrophotofluorometer Fluostar Optima reader (BMG Labtech,

134 Champigny sur Marne, France) with an excitation wavelength set at $355 \mathrm{~nm}$ and emission

135 wavelength set at $460 \mathrm{~nm}$. A control in which $3 \mu \mathrm{L}$ of $0.5 \mathrm{M} \mathrm{CaCl}_{2}$ was replaced by $3 \mu \mathrm{L}$ of 0.5

136 M EDTA was also performed. Enzymatic assays were performed in triplicates and activity was

137 expressed as mean \pm standard deviation. Calpain activity was expressed as fluorescence units per

138 min per $\mathrm{g}$ of muscle (Cheret and others, 2005).

\section{Quantification of calpastatin inhibitory activity}

141 Calpastatin inhibitory activity was measured with a calpain-active sample produced 142 separately from a whole fish white muscle (the nonabsorbed proteins, including calpastatin), as 143 described above. Exactly $55 \mu \mathrm{L}$ of calpastatin sample (or buffer for the control) was mixed with $144200 \mu \mathrm{L}$ of a calpain solution purified separately from a whole fish (Dicentrarchus labrax L.) 145 muscle as described above and the resulting calpain activity was measured on SucLT fluorogenic 146 substrate as previously described. One unit of calpastatin activity was defined as the amount 
147 which inhibits one unit of calpain activity. The values were the means of 3 measurements for 148 each sample (Cheret and others, 2007).

\section{Electrophoresis}

151 Denaturating gel electrophoresis was performed according to method of Laemmli (1970) 152 using Mini-Protean dual slab cell (Bio-Rad, Richmond, CA, USA) using $10 \%$ (w/v) 153 polyacrylamide as the separating gel and 5\% (w/v) polyacrylamide as the stacking gel. Sample 154 was treated at $100^{\circ} \mathrm{C}$ for $5 \mathrm{~min}$ in $1 / 4$ volume of denatured buffer $(10 \mathrm{mM}$ Tris- $\mathrm{HCl} \mathrm{pH} 8,2 \%$ 155 SDS, $0.1 \mathrm{M}$ DTT, $0.01 \%$ bromophenol blue and $1 \mathrm{mM}$ EDTA).

156 Gel electrophoresis under native conditions (PAGE) was carried out on calpain extracts.

157 Samples $(30 \mu \mathrm{L})$ were prepared with $10 \mu \mathrm{L}$ buffer composed of $10 \mathrm{mM}$ Tris- $\mathrm{HCl} \mathrm{pH} 8,0.1 \mathrm{M}$ 158 DTT, $0.01 \%$ bromophenol blue, and $1 \mathrm{mM}$ EDTA, before putting them on the gel.

159 Both denaturated and native electrophoresis gels were silver-stained according to Blum 160 and others (1987).

162 Results and Discussion

163 Effect of high-pressure treatment on the calpain activity

164 Calpain and its specific inhibitor, the calpastatin, were separated by hydrophobic 165 interaction chromatography before measuring calpain activity. Regarding the study on the whole 166 muscle, the purification was performed after the pressurization of the muscle. For the extracted 167 calpain study, the pressurization was done after its purification. In both cases, the activity of 168 calpains decreased significantly when the level of pressure increased (Figure 1). The activity of 169 calpain decrease for pressures higher than $100 \mathrm{MPa}$; and above $350 \mathrm{MPa}$, the high-pressure 170 treatment induced a total loss of activity. Bessière and others (1999a, 1999b) reported that the 
171 high-pressure treatment led to a dissociation of the two subunits of calpains. The corresponding

172 dissociation curve according to the pressure level was similar to our experimental curves. The

173 decrease in activity could therefore be due to the dissociation that is responsible for the instability

174 of the dissociated form (Saido and others 1994). A slight alteration of the calpain structure could 175 also lead to the loss of activity.

\section{Effect of high pressure on the structure of calpain}

178 The calpain was purified by hydrophobic interaction chromatography followed by ion 179 exchange-chromatography. The calpain active fractions were recovered, mixed, and subsequently 180 pressurized at different intensities between 0.1 and $400 \mathrm{MPa}$. The treated samples were studied 181 by native and denatured electrophoresis. Figure 2 shows the effect of high-pressure treatment on 182 the calpain native structure. For the control ( $0.1 \mathrm{MPa})$, only one band was observed, must likely 183 the heterodimeric form. In the pressurized samples, the presence of 2 bands were observed, 184 probably corresponding to the catalytic and regulatory subunits. This indicates that the calpains

185 were dissociated above $100 \mathrm{MPa}$. The SDS-PAGE analysis (Figure 3), showed that the 2 186 observed bands have a molecular weight similar to each calpain subunit, confirming the proposed 187 identification of bands.

189 Effect of high-pressure treatment on the calpain system during the storage

190 Calpain activities after high-pressure treatment were followed during the postmortem 191 storage (the pressures were $0.1,100$, and $300 \mathrm{MPa}$ and the durations of storage were $0,2,4$, and 1927 days) (Figure 4). For the control (0.1 MPa), the calpain activity did not show any evolution 193 during the 7 days of postmortem storage. After pressurization at $100 \mathrm{MPa}$, the initial calpain 194 activity is not affected, but the activity increased between the day 0 and the day 4 and then 
195 decreased at the end of storage. After a pressure treatment at $300 \mathrm{MPa}$, the initial calpain activity

196 was very low and continued to be stable during storage. This latter treatment was apparently too

197 drastic for the calpain molecules and might lead to degradation of the ternary structure.

198 The evolution of calpastatin activity was studied during refrigerated storage after high-pressure

199 treatment of the whole muscle (Figure 5). Initial activity was not affected by pressure treatment

200 but other previous studies have also established that this protein is stable and is resistant to

201 denaturing agents such as urea, SDS, and trichloroacetic acid (Goll and others 2003). Our data

202 confirmed that the protein could also be stable after a high-pressure treatment. The calpastatin

203 activity decreased during postmortem storage. The observed decreased could be due to a

204 degradation of calpastatin (Mellgren and others 1986); therefore calpains could be responsible

205 for the loss of calpastatin activity since the high-pressure treatment has not effect on calpastatin

206 activity.

207

208 Conclusion

209 In summary, we have shown that a high-pressure treatment at $100 \mathrm{MPa}$ is able to

210 dissociate the calpain molecule and to activate it in the first days of storage following the

211 pressurization. After a $300-\mathrm{MPa}$ treatment, calpain is denaturated and in no longer active.

212 Calpastatin initial activity is not affected whatever the intensity of pressure applied and its

213 subsequent decrease upon storage does not depend on the pressure level either. The decrease in

214 activity during storage may be explained by a proteolytic action of the calpains on their own

215 inhibitor. If the calpain system is responsible for fish flesh postmortem degradation as proposed

216 by several authors, such as Jiang (2000), high-pressure treatment at $300 \mathrm{MPa}$ could therefore be a

217 useful way to keep fish flesh at high quality. From a practical and economical point of view, this 
218 technique would be preferentially possible for high value fish fillets. It may be also a good

219 technique for the conservation of a ready to eat.

\section{$221 \quad$ References}

222 Angsupanich K, Ledward DA. 1998. High pressure treatments effects on cod (Gadus morhua)

223 muscle. Food Chem 63(11):39-50.

224 Ashie INA, Simpson BK. 1996. Application of high hydrostatic pressure to control enzyme 225 related fresh seafood texture deterioration. Food Res Int 29(5-6):569-575.

226 Bessière P, Bancel F, Cottin P, Ducastaing A. 1999a. Pressure effects on proteolysis catalysed 227 by calpain. Biochem Mol Biophys 47 (1):25-35.

228 Bessière P, Cottin P, Balny C, Ducastaing A, Bancel F. 1999b. Hydrostatic pressure and 229 calcium-induced dissociation of calpains. Biochim et Biophys Acta 1430:254-261.

230 Blum H, Beier H, Gross HJ. 1987. Improved silver staining of plant proteins, RNA and DNA in 231 polyacrylamide gels. Electrophoresis 8:93-99

232 Chéret R, Delbarre-Ladrat C, de Lamballerie-Anton M, Verrez-Bagnis V. 2005. High-pressure 233 effects on the proteolytic enzymes of sea bass (Dicentrarchus labrax L.) fillets. J Agric Food 234 Chem, 53, 3969-3973.

235 Chéret R, Delbarre-Ladrat C, de Lamballerie-Anton M, Verrez-Bagnis V. 2007. Comparison of 236 proteolytic enzyme activities in fish and meat muscle. Food Chem, 101(4): 1474-1479.

238 Deliza R, Rosenthal A, Adabio FBD, Silva CHO, Castillo C. 2005. Application of high pressure 239 technology in fruit juice processing: benefits perceived by consumers. J Food Eng 67(1-2):241240246. 
241 Goll DE, Thompson VF, Li H, Wei W, Cong J. 2003. The calpain system. Physiol Rev 83:731-

242801.

243 Gornall AG, Bardawill CJ, David MM. 1949. Determination of serum proteins by means of the

244 biuret test. J Biol Chem 177:751-766.

245 Jiang ST. 2000. Effect of proteinases on meat texture and seafood quality. Food Sci Agri Chem $246 \quad 2(2): 55-74$.

247 Ladrat C, Chaplet M, Verrez-Bagnis V, Noelle J, Fleurence J. 2000. Neutral calcium-activated

248 proteases from European sea bass (Dicentrachus labrax L.) muscle: polymorphism and

249 biochemical studies. Comp Biochem Physiol 125 B: 83-95.

250 Laemmli UK. 1970. Cleavage of structural proteins during the assembly of the head of

251 bacteriophage T4. Nature, 227:680-685.

252 Mellgren RL, Mericle MT, Lane RD. 1986. Proteolysis of the calcium-dependent protease

253 inhibitor by myocardial calcium-dependent protease. Arch Biochem Biophys 246(1):233-9.

254 Ohshima T, Ushio H, Koizumi C. 1993. High pressure processing of fish and fish products.

255 Trends Food Sci Technol 4:370-375.

256 Saido TC, Sorimachi H, Suzuki K. 1994. Calpain: new perspectives in molecular diversity and 257 physiological-pathological involvement. FASEB J 8:814-822.

258 Yuste J, Capellas M, Pla R, Fung DYC, Mor-Mur MM. 2001. High pressure processing for food 259 safety and preservation: a review. J Rapid Meth Automation Microbiol 9:1-10. 


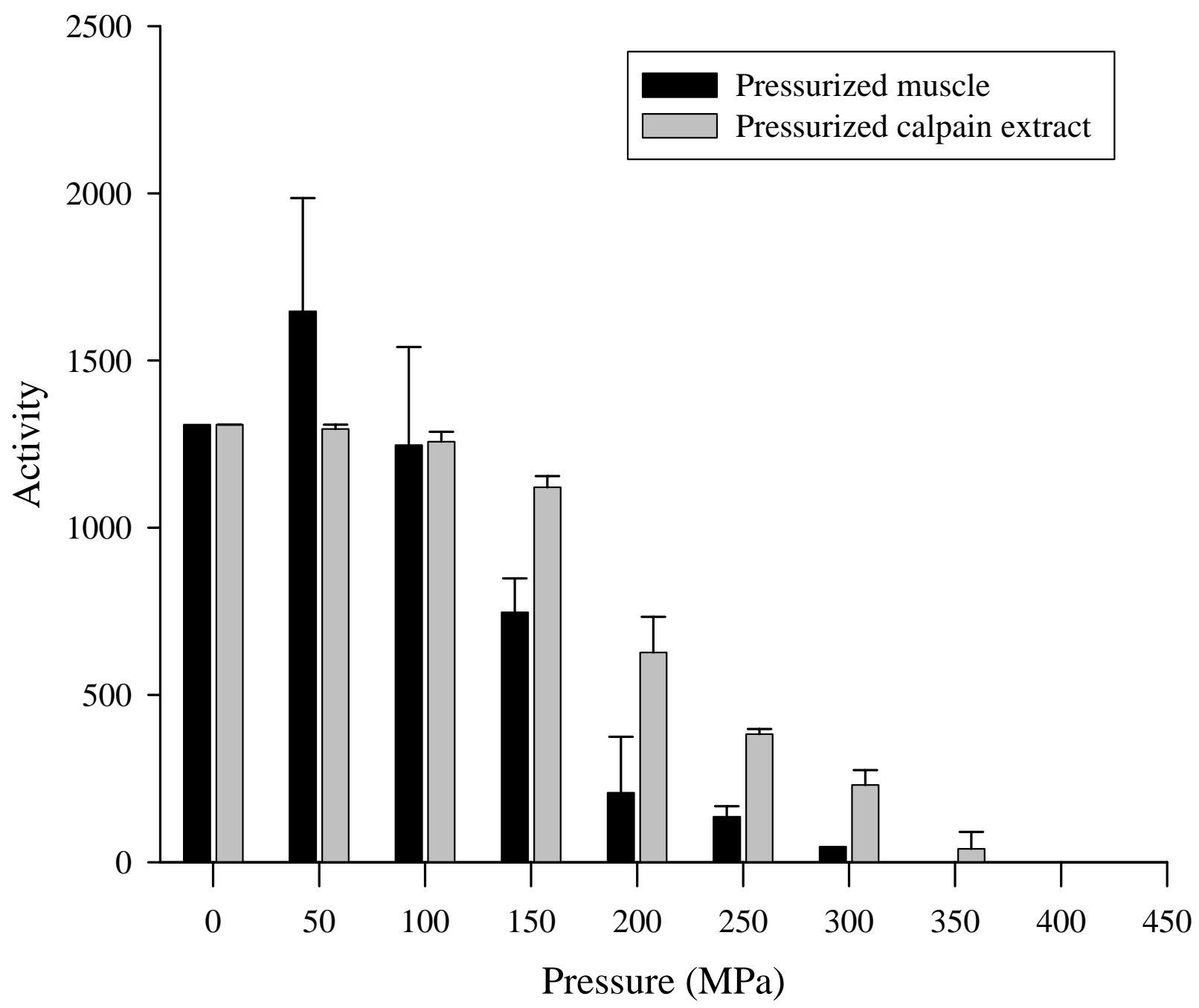

263 Figure.1. Evolution of calpain activity according to the pressure applied on calpain extract and on

264 fish white muscle. Results are means of 3 samples; the vertical bars represent the standard 265 deviation. The activities are expressed in fluorescence units per minute per $\mathrm{g}$ of muscle. 


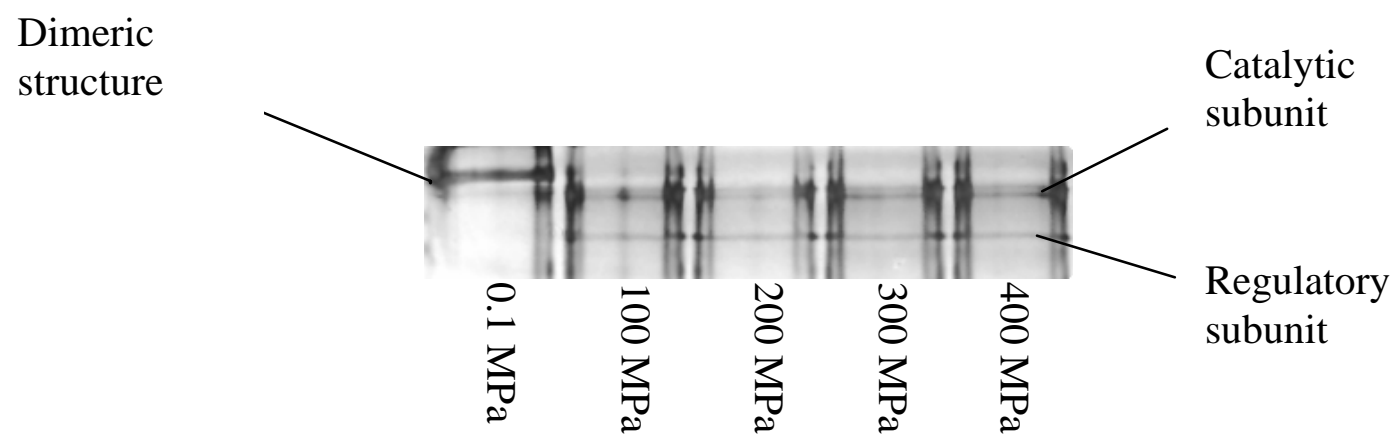

270 Figure. 2. Native PAGE of calpains from fish (Dicentrarchus labrax L.) white muscle after high271 pressure treatment $(0.1,100,300$ and $400 \mathrm{MPa})$. 

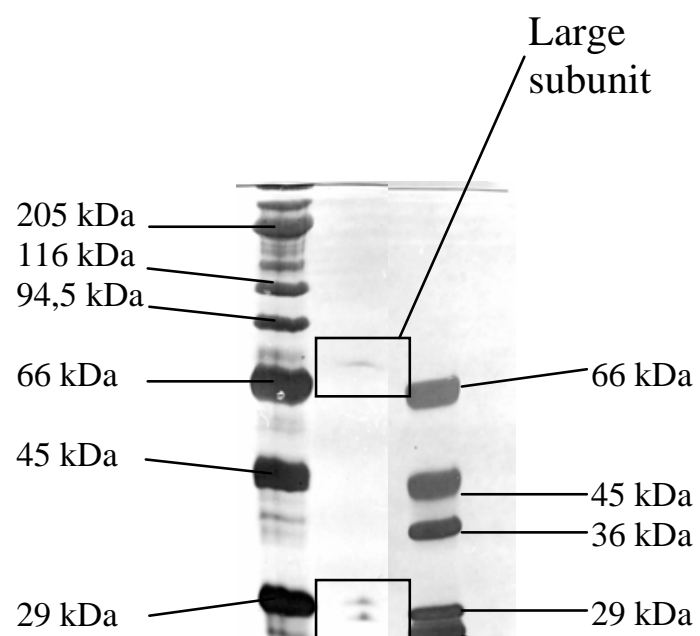

279

283 Figure. 3. Analysis of calpains by SDS PAGE from fish (Dicentrarchus labrax L.) white muscle 284 after purification. 


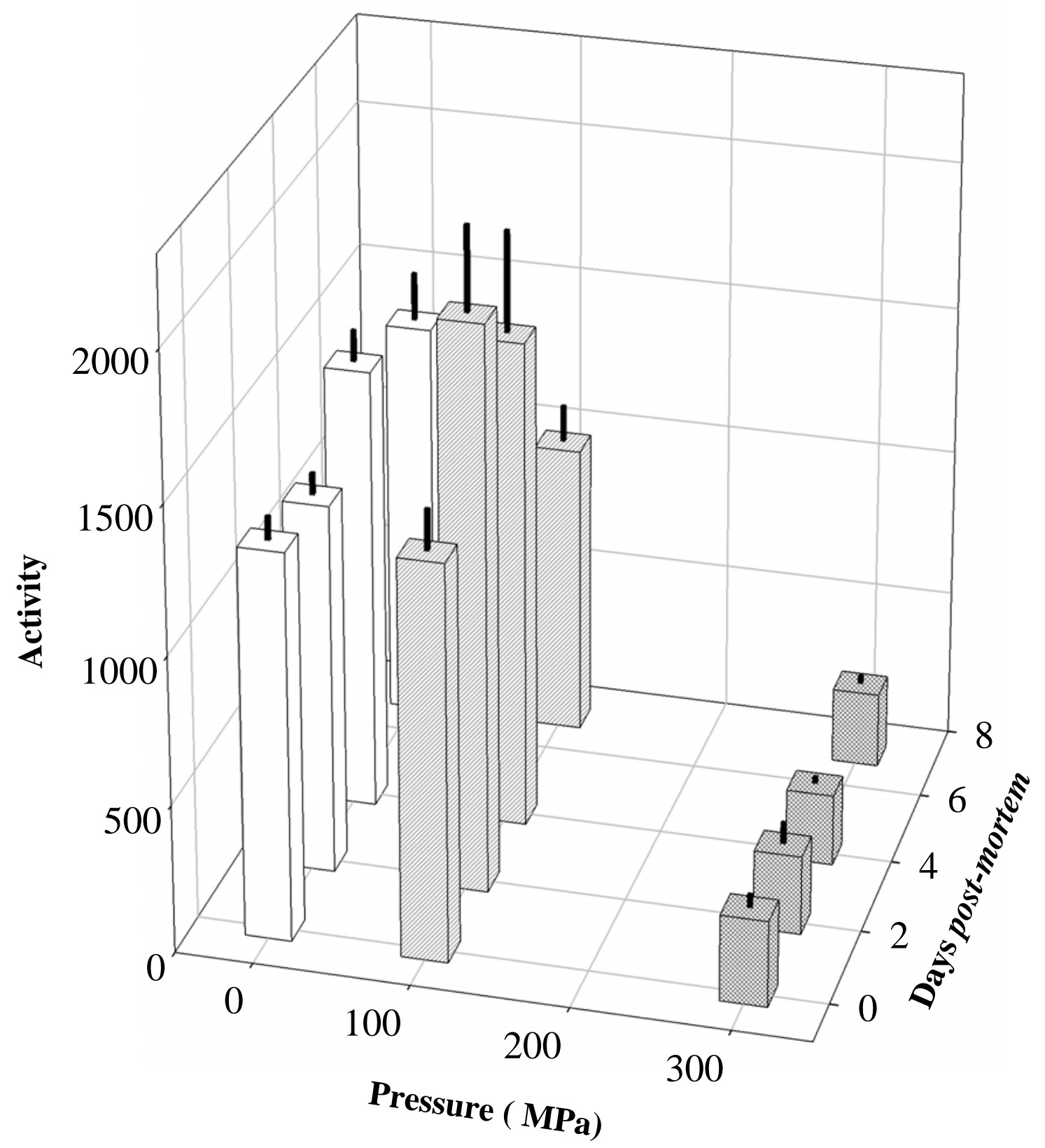

286 Figure. 4. Changes of calpain activities after 0, 2, 4, and 7 days post-mortem for the different 287 pressurized muscle samples: $0.1 \mathrm{MPa}$ (control sample), $100 \mathrm{MPa}$, and $300 \mathrm{MPa}$. Results are 288 means ( \pm S.D.) of 3 measurements; the vertical bars represent the standard deviation. The 289 activities are expressed in fluorescence units per minute per $\mathrm{g}$ of muscle. 


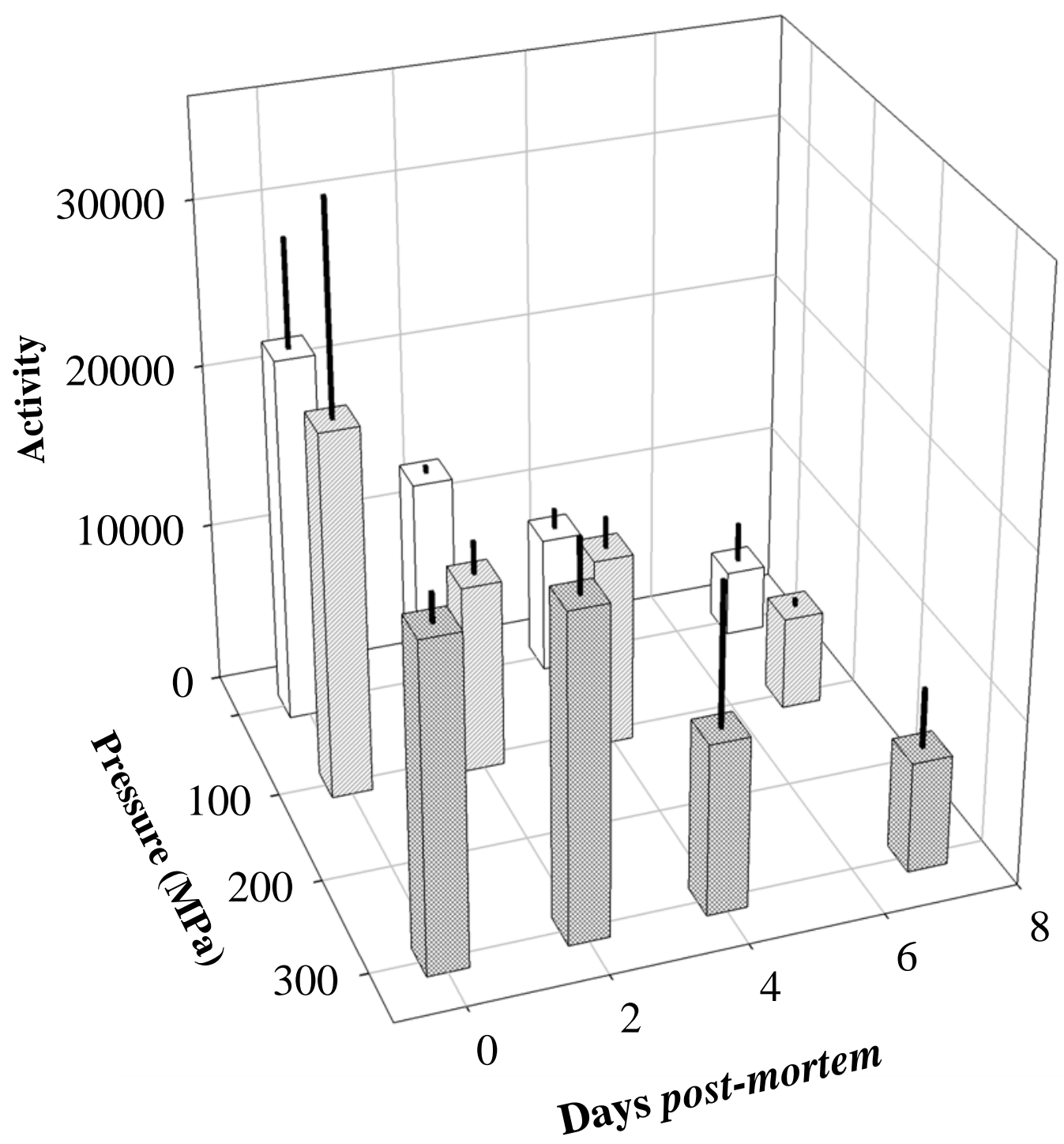

291 Figure. 5. Changes of the calpastatin activities after 0, 2, 4 and 7 days post-mortem after 292 pressurization of muscle samples at $0.1 \mathrm{MPa}$ (control), $100 \mathrm{MPa}$, and $300 \mathrm{MPa}$. Results are 293 means ( \pm S.D.) of 3 measurements; the vertical bars represent the standard deviation. One unit is 294 able to inhibit one unit (fluorescence unit per minute per g of muscle) of calpain. 